\title{
Diversity of Millipedes in Alagar Hills Reserve Forest in Tamil Nadu, India
}

\author{
Periasamy Alagesan and Baluchamy Ramanathan \\ Post Graduate and Research Department of Zoology, Yadava College, Madurai, Tamil Nadu 625 014, India \\ Correspondence should be addressed to Periasamy Alagesan; maniragavi@rediffmail.com
}

Received 10 September 2012; Revised 10 December 2012; Accepted 14 January 2013

Academic Editor: Curtis C. Daehler

Copyright (C) 2013 P. Alagesan and B. Ramanathan. This is an open access article distributed under the Creative Commons Attribution License, which permits unrestricted use, distribution, and reproduction in any medium, provided the original work is properly cited.

Millipede diversity and abundance were analysed at sites lying between 250 and 650 meters above mean sea level in Alagar Hills of Eastern Ghats, Tamil Nadu, India. Millipede abundance and diversity peaked at midelevations influenced by favourable niche and food resources. Diversity of millipedes indicates the influence of local habitat and food resource availability. In the present study, millipede species, Harpaphe haydeniana, Xenobolus carnifex, Arthrosphaera magna, Aulacobolus newtoni, and Spinotarsus colosseus, are present at midelevation (450 MSL). Abundance of millipedes at $450 \mathrm{~m}$ elevation is due to moderate canopy and litter, which support understorey vegetation like herbs and shrubs.

\section{Introduction}

Biodiversity offers several direct and indirect economic benefits to humankind [1]. The interest in diversity especially over the past few years has focused on how diversity influences ecosystems and ecological processes [2]. Ninety-five percent of experimental studies support a positive relationship between diversity and ecosystem functioning [3-5]. The biotic diversity tends to play a significant role by enriching the soil, maintaining water and climatic cycles, and converting waste materials into nutrients. Soil macrofauna makes an important contribution to soil fertility by promoting the stability and productivity of forest ecosystems, mainly due to their influence on soil process such as litter decomposition and nutrient dynamics [6]. Furthermore, elevation is merely a surrogate for a suite of biotic and abiotic factors that influence species richness [7]. Therefore, identifying ecologically meaningful causal factors is essential in order to explain variation in species richness along elevation gradients [8]. Millipedes belong to class Diplopoda, a highly diverse group of terrestrial organisms with over 12,000 described species and an estimated 80, 000 species yet to be described $[9,10]$. Among soil Arthropods, millipedes act as primary destructors of plant debris and play a crucial role in soil formation processes. Many millipedes can also serve as indicators of environmental conditions and improve the structure content of organic matter and nutrient elements of soil [11, 12].

Gadagkar et al. [13] studied species richness and diversity of ant populations from different localities in Western Ghats, India. Diversity of forest litter-inhabiting ants along an elevation gradient in the Wayanad region of the Western Ghats is studied by Sabu et al. [14]. Bharti and Sharma [15] observed the diversity and abundance of ants along an elevational gradient in Jammu Kashmir, the Himalayas. Bubesh Guptha et al. [16] examined the preliminary observation on butterflies of Seshachalam biosphere reserve, Eastern Ghats, Andhra Pradesh, India. Diversity indices of tropical cockroach were reported by Bonsals [17] and Padmanaban [18]. Distribution, diversity, and population dynamics of chosen insects in Courtallam tropical evergreen forest were extensively studied by Edwin [19]. Anu et al. [20] studied litter arthropod diversity in an evergreen forest in the Wayanad region of Western Ghats, India. Biodiversity of spiders in Western Ghats of Tamil Nadu was also reported [21, 22]. Isabel [23] observed biodiversity of litter arthropod communities in Alagar Hills Reserve forest in Eastern Ghats, India. In India there is no proper information available on the identification, the diversity, and the role of millipedes in forest ecosystems. Hence, the broad objective of the present study is to identify 
and calculate the diversity indices of millipedes species along an elevation gradient within the Alagar Hills Reserve forest of Eastern Ghats, India.

\section{Materials and Methods}

2.1. Study Area. Alagar Hills, a biosphere evergreen reserve in Tamil Nadu, is located in Eastern Ghats $\left(10^{\circ} 0^{\prime}-10^{\circ} 30^{\prime} \mathrm{N}\right.$ and $\left.75^{\circ} 55^{\prime}-78^{\circ} 20^{\prime} \mathrm{E}\right), 20 \mathrm{~km}$ northeast of Madurai city, India. The vegetation is two layered, in which the ground vegetation is very poor. The canopy is open dry deciduous or evergreen vegetation. Five locations were selected at different altitudes at Alagar hills (250, 350, 450, 550, and $650 \mathrm{~m}$ ), which were visited every month from July 2011 to May 2012. The lowest site was at $250 \mathrm{~m}$ elevation because that is where millipedes seemed to first occur, while $650 \mathrm{~m}$ is the highest elevation of Alagar hills reserve forest. Observation of millipedes was made through 6 quadrats $(1 \mathrm{~m} \times 1 \mathrm{~m})$ in each study site and each sampling date, and the mean number of millipedes/quadrat was calculated. Millipedes were collected from the study area by hand picking, and species were identified by using various field guides and available literatures.

2.2. Data Analysis. Standard methods were used to calculate the richness and evenness of millipede species at different altitudes. The diversity indices were calculated using the Ludwig and Reyonlds software package [24]. Two indices are needed to compute Hill's diversity numbers: (a) Simpson's index and (b) Shannon's index. These were calculated by using the following formulae:

Simpson's index $(\lambda)$ :

$$
\lambda=\sum_{i=1}^{s} \frac{n_{i}\left(n_{i}-1\right)}{n(n-1)},
$$

Shannon's index $\left(H^{\prime}\right)$ :

$$
H^{\prime}=\sum_{i=1}^{s}\left[\left(\frac{n_{i}}{n}\right) \ln \left(\frac{n_{i}}{n}\right)\right] .
$$

\section{Results}

The following five species of millipedes were identified in the study area.

(1) Harphaphe haydeniana (Wood, 1984) belongs to order Polydesmida and family Xystodesmidae. $H$. haydeniana is a yellow spotted millipede and reaches a length of $4-5 \mathrm{~cm}$, width of 0.1 to $0.3 \mathrm{~cm}$, and weight of 0.8 to $1.5 \mathrm{~g}$. The body is black and is distinctively marked along the sides with patches of a yellowish colour. It consists of approximately 15-20 body segments, bearing a total of 30 (male) or 31 (female) pairs of legs. It lives for 2-3 years. (Figure 1).

(2) Arthrosphaera magna (Attems, 1936) belongs to order Sphaerotheriida and family Sphaerotheriidae. Adults have exactly 13 segments (including collum and anal

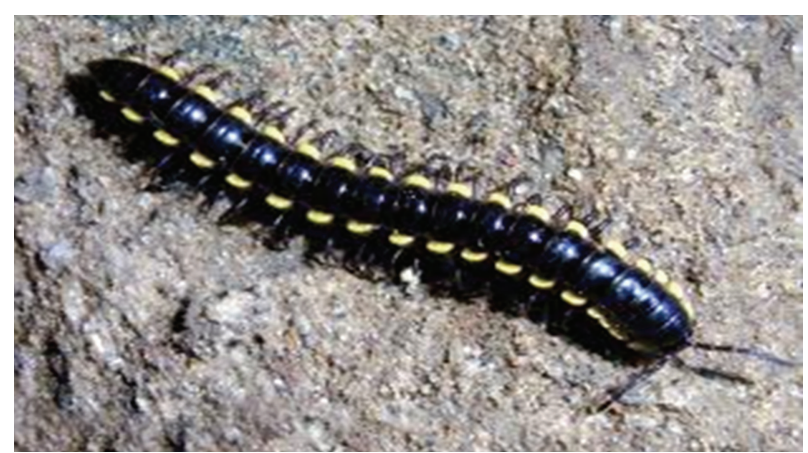

FIGURE 1: Harpaphe haydeniana.

segments), and the juveniles are of dark olive green colour. The head of the adult is yellow brown or olive brown or olive green; the second segment is dark brown with a black band bordered with yellow colour, forming a narrow stripe. The average weight, length, and width of an adult millipede range from 4.5 to $12.5 \mathrm{~g}$, from 3.5 to $6.5 \mathrm{~cm}$, and from 1.5 to $2.5 \mathrm{~cm}$, respectively, (Figure 2).

(3) Xenobolus carnifex (Fabricius, 1775) belongs to order Spirobolida and family Pachybolidae. The body segments are black with a broad median band of dark pink colour. Adults have exactly 50 segments and attain an average length of $6 \mathrm{~cm}$ and width of $0.5 \mathrm{~cm}$. The seventh segment in the male is without legs. The sexes are easily distinguishable from the fifth stadium based on their length and width. Adult males have an average body width of $0.8 \mathrm{~cm}$ and weight of $7.8 \mathrm{~g}$, whereas the adult female has an average midsegment width of $0.9 \mathrm{~cm}$. and weight of $8.5 \mathrm{~g}$ (Figure 3 ).

(4) Aulacobolus newtoni (Silvestri, 1916) belongs to order Spirobolida and family Pachybolidae. Both sexes exhibit dark greenish yellow colouration, and the maximum number of body segments is 50 . Adult males have a width of $0.8 \mathrm{~cm}$ and an average weight of $7.8 \mathrm{~g}$, whereas the adult female has an average weight of $8.5 \mathrm{~g}$ and midsegment width of $0.9 \mathrm{~cm}$. The body length of both male and female ranges from 8.0 to $9.5 \mathrm{~cm}$ (Figure 4).

(5) Spinotarsus colosseus (Attems, 1928) belongs to order Spirostreptida and family Odontopygidae. Both males and females of $S$. colosseus are of darkblack colour. The length, width, and weight of the millipede range from $6.5-15.4 \mathrm{~cm}, 0.3-1.0 \mathrm{~cm}$, and $5.5-15.7 \mathrm{~g}$, respectively. The number of body segments in adult is $55-58$. (Figure 5).

The maximum number of millipedes $\left(721 / \mathrm{m}^{2}\right)$ was observed at $450 \mathrm{~m}$ and the minimum $\left(251 / \mathrm{m}^{2}\right)$ was observed at $650 \mathrm{~m}$ elevation (Figure 6). The density of millipedes decreased in the order of $350 \mathrm{~m}\left(393 / \mathrm{m}^{2}\right), 550 \mathrm{~m}\left(387 \mathrm{~m}^{2}\right)$, and $250 \mathrm{~m}$ $\left(251 / \mathrm{m}^{2}\right)$ elevations. Richness indices $\left(R_{1}: 0.607 ; R_{2}: 0.186\right)$ and Simpson's index (0.207) were found to be lower in the midelevation $(450 \mathrm{~m})$ than in the other elevations (Table 1). 
TABLE 1: Diversity of five different species of millipedes distributed at five elevations of Alagar hills reserve forest.

\begin{tabular}{lcccccr}
\hline \multicolumn{2}{l}{ Indices } & & \multicolumn{2}{c}{ Elevations } \\
& & $250 \mathrm{~m}$ & $350 \mathrm{~m}$ & $450 \mathrm{~m}$ & $550 \mathrm{~m}$ & $0.60 \mathrm{~m}$ \\
\hline \multirow{2}{*}{ Richness } & $R_{1}$ & 0.720 & 0.669 & 0.607 & 0.723 \\
& $R_{2}$ & 0.311 & 0.252 & 0.186 & 0.254 & 0.315 \\
\multirow{2}{*}{ Diversity } & Simpson's index & 0.222 & 0.215 & 0.207 & 0.213 & 0.223 \\
& Shannon's index & 1.539 & 1.562 & 1.589 & 1.561 \\
Evenness & $E$ & 0.955 & 0.970 & 0.981 & 0.969 & 0.924 \\
\hline
\end{tabular}



Figure 2: Arthrosphaera magna.

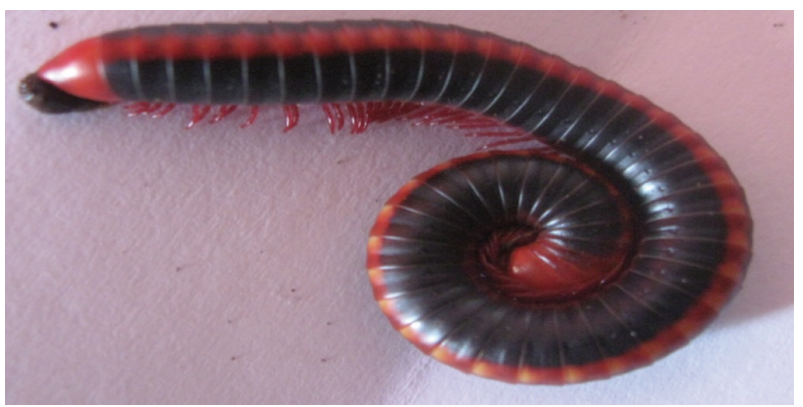

FIGURE 3: Xenobolus carnifex.

Remarkably, a very high evenness (0.981) was noticed in $450 \mathrm{~m}$ elevation. With reference to Shannon's index, it was found to decrease from 1.589, 1.562, 1.561, 1.539, and 1.489 at $450,350,550,250$ and $650 \mathrm{~m}$ elevations, respectively.

\section{Discussion}

The present study, an inventory of millipedes, is the first of its kind in Alagar hills of Eastern Ghats. Also, this is the first report of the elevational distribution of millipedes in the Eastern Ghats of Alagar hills. Two diversity indices were calculated. Shannon's index $\left(H^{\prime}\right)$ is sensitive to changes in the abundance of rare species in a community, whereas Simpson's index $(\lambda)$ is sensitive to changes of the most abundant species in a community. These two diversity indices showed much difference in millipede distribution and diversity. Shannon index assumes that individuals are randomly sampled from an indefinitely large population [25]. This index also assumes

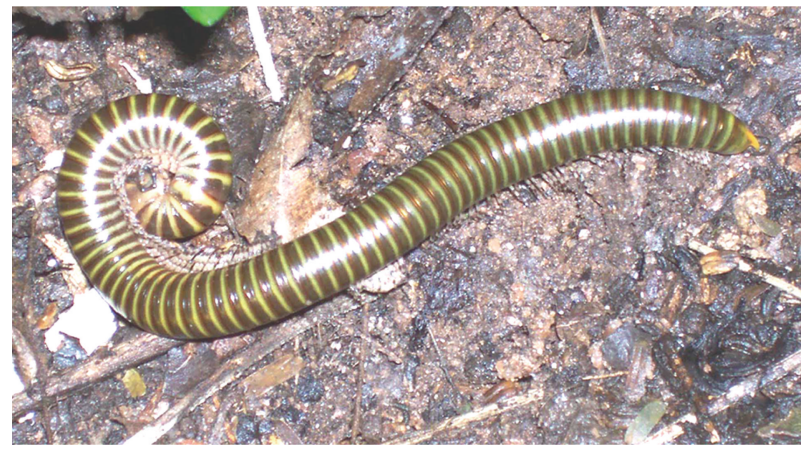

Figure 4: Aulacobolus newtoni.

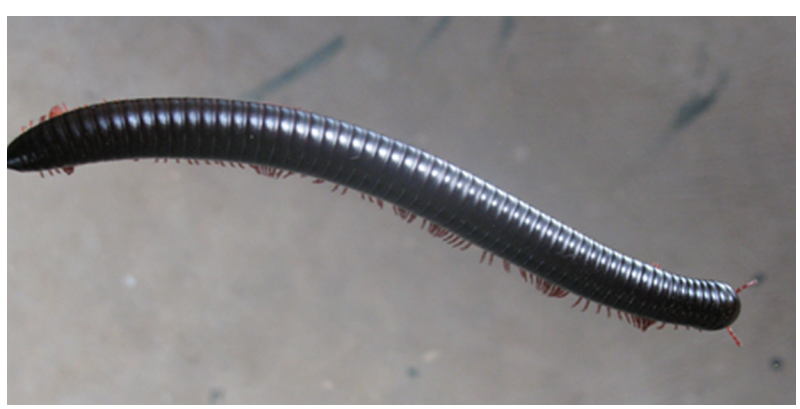

FIGURE 5: Spinotarsus colosseus.

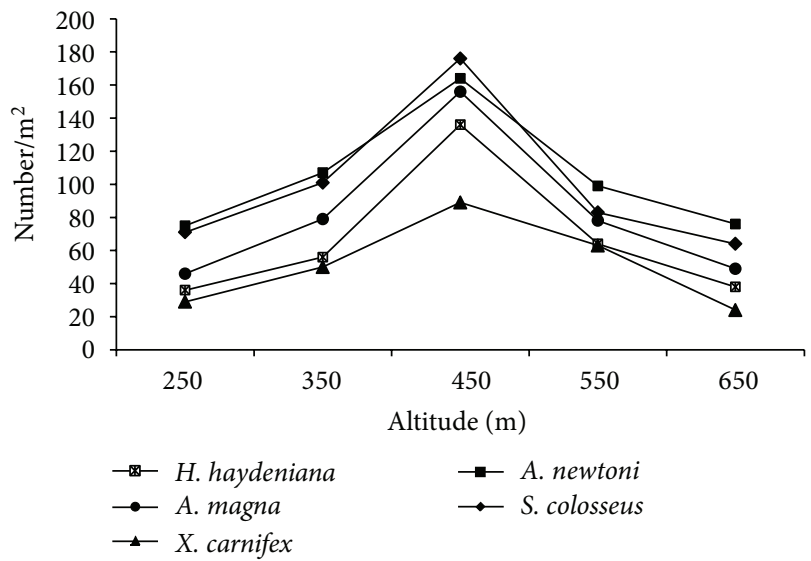

FIgURE 6: Density of different millipede species in the study sites of Alagar Hills. 
that all millipedes are represented in the sample. Simpson's index, which gives the probability of two individuals drawn at random from a population belonging to the same species, increases with the decrease in diversity. Hence, it is understood that midelevation has the highest diversity, and low and highest elevations have the lowest diversity pattern.

Brown [26] reported that changes in life on earth are due to abundance and diversity of organisms along the earth major environmental gradients, including those of elevation.

The significant change of abiotic and biotic environmental variables along elevational gradients strongly affects patterns of abundance, distribution, and diversity of most organisms. As emphasized by Brown and Lomolino [27], lower elevational zones usually differ from higher altitude by the following: (1) a greater total amount of resources and population number; (2) more refugia and space for species with large home ranges; (3) greater habitat diversity; and (4) a greater potential for serving as a target for potential immigrants. The abundance of feeding guilds can strongly depend on habitat structure [28] which changes with increasing altitude, thereby differentially altering the available amount of food resources for feeding guilds and the vegetation structures required for foraging by different functional groups along the elevation gradient [29].

The present study reveals the fact that maximum millipede species diversity in midelevation, which confirms to the midelevational richness in species abundance is recorded from Philippines by Samson et al. [30] and from Madagascar by Fisher [31]. The higher Shannon's diversity index shown by middle elevation indicates that it provides more opportunities for survival in the form of ecological niches than those lower and higher elevations. The lower level of elevation is highly disturbed due to human activities and cattle grazing. The canopy cover is open, which results in nearly dry and barren land rendering fewer potential niches. The boulders, which are very common, have been used only as a shelter from extremes of temperature and humidity during summer. In high elevation, the closed canopy reduces the sunlight and the under storey vegetation which again results in a reduced number of potential niches. Besides, the high rate of transpiration by plants and nearby water streams makes the atmosphere very humid and cool. This could be the reason for moderate evenness and diversity indices shown by these elevations. But, the middle elevation with moderate canopy and litters supports understorey vegetation like herbs and shrubs and provides more potential niches and protection during periodic flooding. This elevation is occupied by all species of millipedes in fairly equal proportion, and this explains the high evenness and diversity indices observed in midelevation.

Cardelús et al. [32] emphasized that many species from lower and higher elevations overlap at midelevation, which generally provides the most suitable environment for arthropods. Sabu et al. [14] commented that peak litter ant abundance recorded at midelevations in the Wayanad region suggests that these are centres of the richest diversity and abundance. Rahbek [7] demonstrated that hump-shaped relationship with maximum species numbers at midelevations. Different elevational richness pattern may be due to (a) an overall decline of species richness with increasing altitude [33], (b) a plateau of species being the richest at lower altitude then declining towards the highest elevations [34], and (c) a midelevation peak of species richness $[35,36]$. Padmanaban [18] reported that cockroach diversity and abundance were the maximum in the middle altitudes in comparison with those in the higher and lower altitudes of Alagar hills reserve forest., Isabel [23] also emphasized that arthropod species diversity was higher in midelevations compared to that in lower and higher elevations of Alagar hills.

Krebs [37] consolidated six reasons out of the hypotheses proposed for variation in species diversity, namely, time available for speciation and dispersal, spatial heterogeneity, vegetation structure, competition, environmental stability, and productivity. These reasons can be attributed to the variation in diversity indices between elevations observed in the present study. From the present study, it is concluded that distinct variations in the diversity of millipedes at five different altitudes and peak diversity of millipedes recorded at midlevel elevations in the Alagar hills suggest that these are centres of the richest diversity and abundance that should be prioritised as areas for further intense conservation.

\section{Acknowledgments}

The authors are thankful to the University Grants Commission, New Delhi, India, for providing grants in the form of Major Research Project for this research. Editorial improvements by Cutis C. Daehler are gratefully acknowledged.

\section{References}

[1] P. R. Ehrlich and A. H. Ehrlich, "The value of biodiversity," Ambio, vol. 21, no. 3, pp. 219-226, 1992.

[2] D. Tilman, "The ecological consequences of changes in biodiversity: a search for general principles," Ecology, vol. 80, no. 5, pp. 1455-1474, 1999.

[3] A. Purvis and A. Hector, "Getting the measure of biodiversity," Nature, vol. 405, no. 6783, pp. 212-219, 2000.

[4] K. S. . McCann, “The diversity-stability debate," Nature, vol. 405, pp. 228-233, 2000.

[5] P. Jaen-Francois, "Interaction between soilfauna and their environment," Soil Fauna Environment, pp. 45-76, 1999.

[6] U. Irmler, "Changes in the fauna and its contribution to mass loss and $\mathrm{N}$ release during leaf litter decomposition in two deciduous forests," Pedobiologia, vol. 44, no. 2, pp. 105-118, 2000.

[7] C. Rahbek, "The elevational gradient of species richness: a uniform pattern?” Ecography, vol. 18, no. 2, pp. 200-205, 1995.

[8] R. Naniwadekar and K. Vasudevan, "Patterns in diversity of anurans along an elevational gradient in the Western Ghats, South India," Journal of Biogeography, vol. 34, no. 5, pp. 842853, 2007.

[9] R. M. Shelley, “Taxonomy of extant Diplopoda (Millipeds) in the modern era: perspectives for future advancements and observations on the global diplopod community (Arthropoda: Diplopoda)," Zootaxa, no. 1668, pp. 343-362, 2007.

[10] P. Sierwald and J. E. Bond, "Current status of the myriapod class diplopoda (millipedes): taxonomic diversity and phylogeny," Annual Review of Entomology, vol. 52, pp. 401-420, 2007. 
[11] G. Loranger-Merciris, D. Imbert, F. Bernhard-Reversat, J. F. Ponge, and P. Lavelle, "Soil fauna abundance and diversity in a secondary semi-evergreen forest in Guadeloupe (Lesser Antilles): influence of soil type and dominant tree species," Biology and Fertility of Soils, vol. 44, no. 2, pp. 269-276, 2007.

[12] J. Seeber, G. U. H. Seeber, R. Langel, S. Scheu, and E. Meyer, “The effect of macro-invertebrates and plant litter of different quality on the release of $\mathrm{N}$ from litter to plant on alpine pastureland," Biology and Fertility of Soils, vol. 44, no. 5, pp. 783-790, 2008.

[13] R. Gadagkar, K. Chandrasekaran, and D. M. Bhat, "Ant species richness and diversity in some selected localities in Western Ghats, India," Hexpoda, vol. 5, no. 2, pp. 79-94, 1993.

[14] T. K. Sabu, P. J. Vineesh, and K. V. Vinod, "Diversity of forest litter-inhabiting ants along elevations in the Wayanad region of the Western Ghats," Journal of Insect Science, vol. 8, article 69, 2008.

[15] H. Bharti and Y. P. Sharma, "Diversity and abundance of ants along an elevational gradient in Jammu-Kashmir Himalaya," Halteres, vol. 1, pp. 10-24, 2009.

[16] M. Bubesh Guptha, D. Chalapathi Rao, and D. Srinivas Reddy, "A preliminary observation on butterflies of Seshachalam Biosphere Reserve, Eastern Ghats, Andrapradesh, India," World Journal of Zoology, vol. 7, pp. 83-89, 2012.

[17] M. B. . Bonsals, "Domiciciary cockroach diversity in Ecuador," Endomologist, pp. 14431-14439, 1995.

[18] A. . Padmanaban, Distribution, population dynamics and biodiversity of litter dwelling feral cockroaches in Alagar hill reserve forest of Eastern Ghats [Ph.D thesis], Madurai Kamaraj University, Madurai, India, 2002.

[19] J. Edwin, Distribution, diversity and population dynamics of chosen insects in the Courtallam tropical evergreen forest [Ph.D. dissertation], Madurai Kamaraj University, Madurai, India, 1997.

[20] A. Anu, T. K. Sabu, and P. J. Vineesh, "Seasonality of litter insects and relationship with rainfall in a wet evergreen forest in south western Ghats," Journal of Insect Science, vol. 9, article 46, 2009.

[21] M. . Sugumaran, M. Ganesh Kumar, and K. Ramasamy, "Biodiversity of spiders in Western Ghats of Tamil Nadu," Entomon, vol. 30, pp. 157-163, 2005.

[22] H. Upamanyu and V. P. Uniyal, "Diversity and composition of spider assemblages in five vegetation types of the Terai Conservation Area, India," Journal of Arachnology, vol. 36, no. 2, pp. 251-258, 2008.

[23] W. Isabel, Litter dynamics and biodiversity of litter Arthropod Communities [Ph.D thesis], Madurai Kamaraj University, Madurai, India, 2002.

[24] J. A. Ludwig and J. F. Reyonlds, Statistical ecology. A primer on methods and computing richness evenness and species diversity, John Wiley and Sons, New York, NY, USA, 1988.

[25] C. PeilouE, Ecological Diversity, Wiley Eastern, New York, NY, USA, 1975.

[26] J. H. Brown, "Mammals on mountainsides: elevational patterns of diversity," Global Ecology and Biogeography, vol. 10, no. 1, pp. 101-109, 2001.

[27] J. Brown and M. V. Lomolino, Biogeography, Sinauer, Sunderland, Mass, USA, 2nd edition, 1998.

[28] H. Brunner, "Vogelgemeinschaften an der oberen Waldgrenze unter dem Einfluss traditioneller und moderner Landnutzung im Nockgebiet (Karnten, steiermark), Carinthia, Jahrgang," pp. 533-544, 2001.

[29] J. G. Blake and B. A. Loiselle, "Diversity of birds along an elevational gradient in the Cordillera Central, Costa Rica," The Auk, vol. 117, no. 3, pp. 663-686, 2000.
[30] D. A. Samson, E. A. Rickart, and P. C. Gonzales, "Ant diversity and abundance along an elevational gradient in the Philippines," Biotropica, vol. 29, no. 3, pp. 349-363, 1997.

[31] B. L. Fisher, "Ant diversity pattern along an elevational gradient in the Reserve Speciale de Manongarivo, Madagascar," Boissiera, vol. 59, pp. 311-328, 2002.

[32] C. L. Cardelús, R. K. Colwell, and J. E. Watkins, "Vascular epiphyte distribution patterns: explaining the mid-elevation richness peak," Journal of Ecology, vol. 94, no. 1, pp. 144-156, 2006.

[33] F. Sergio and P. Pedrini, "Biodiversity gradients in the Alps: the overriding importance of elevation," Biodiversity and Conservation, vol. 16, no. 12, pp. 3243-3254, 2007.

[34] S. K. Herzog, M. Kessler, and K. Bach, “The elevational gradient in Andean bird species richness at the local scale: a foothill peak and a high-elevation plateau," Ecography, vol. 28, no. 2, pp. 209222, 2005.

[35] M. Kessler, S. K. Herzog, J. Fjeldså, and K. Bach, "Species richness and endemism of plant and bird communities along two gradients of elevation, humidity and land use in the Bolivian Andes," Diversity and Distributions, vol. 7, no. 1-2, pp. 61-77, 2001.

[36] P. F. Lee, M. Kessler, and R. R. Dunn, "What drives elevational patterns of diversity? A test of geometric constraints, climate and species pool effects for pteridophytes on an elevational gradient in Costa Rica," Global Ecology and Biogeography, vol. 15, no. 4, pp. 358-371, 2006.

[37] C. J. Krebs, The Experimental Analysis of Distribution and Abundance, Harper and Row, New York, NY, USA, 1972. 

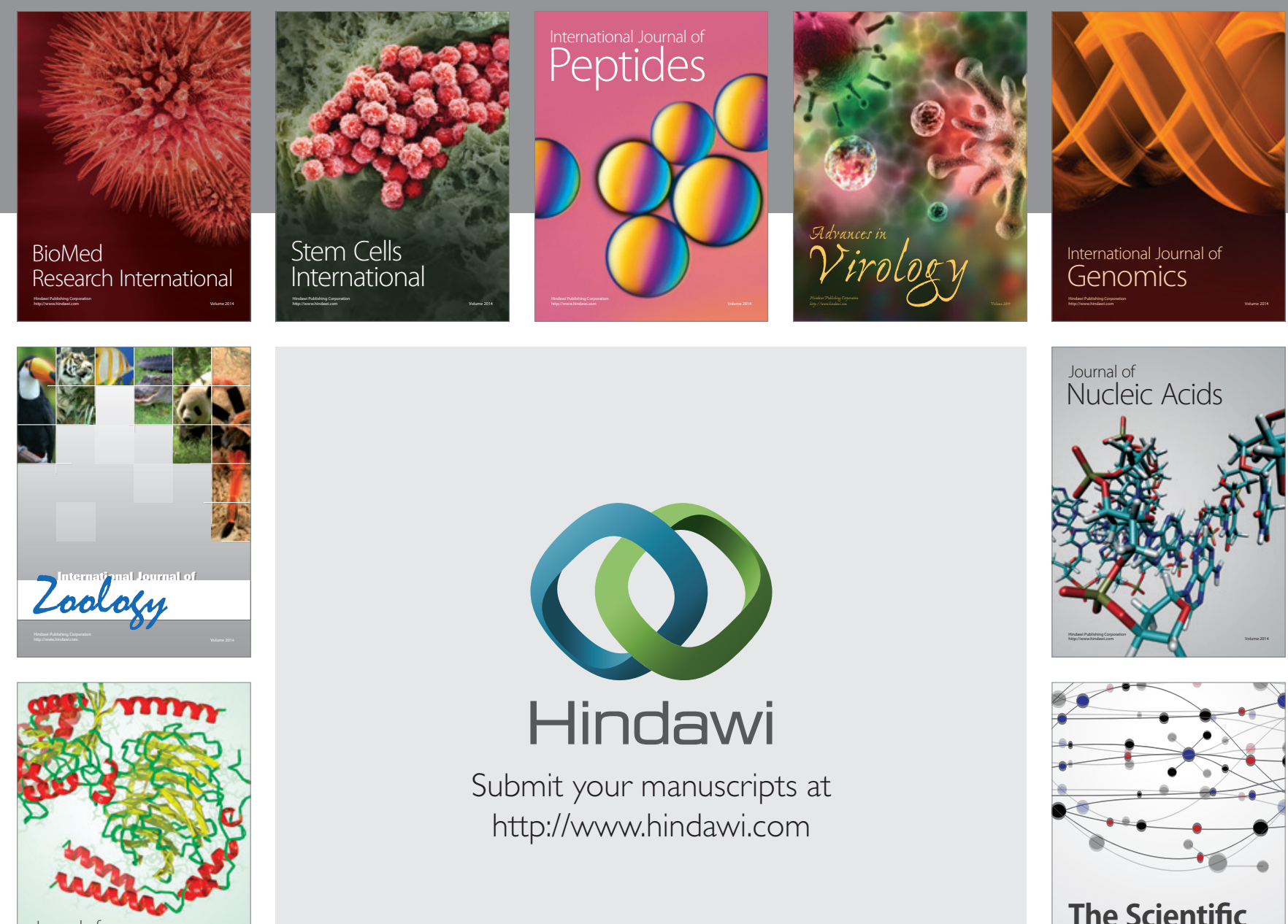

Submit your manuscripts at

http://www.hindawi.com

Journal of
Signal Transduction
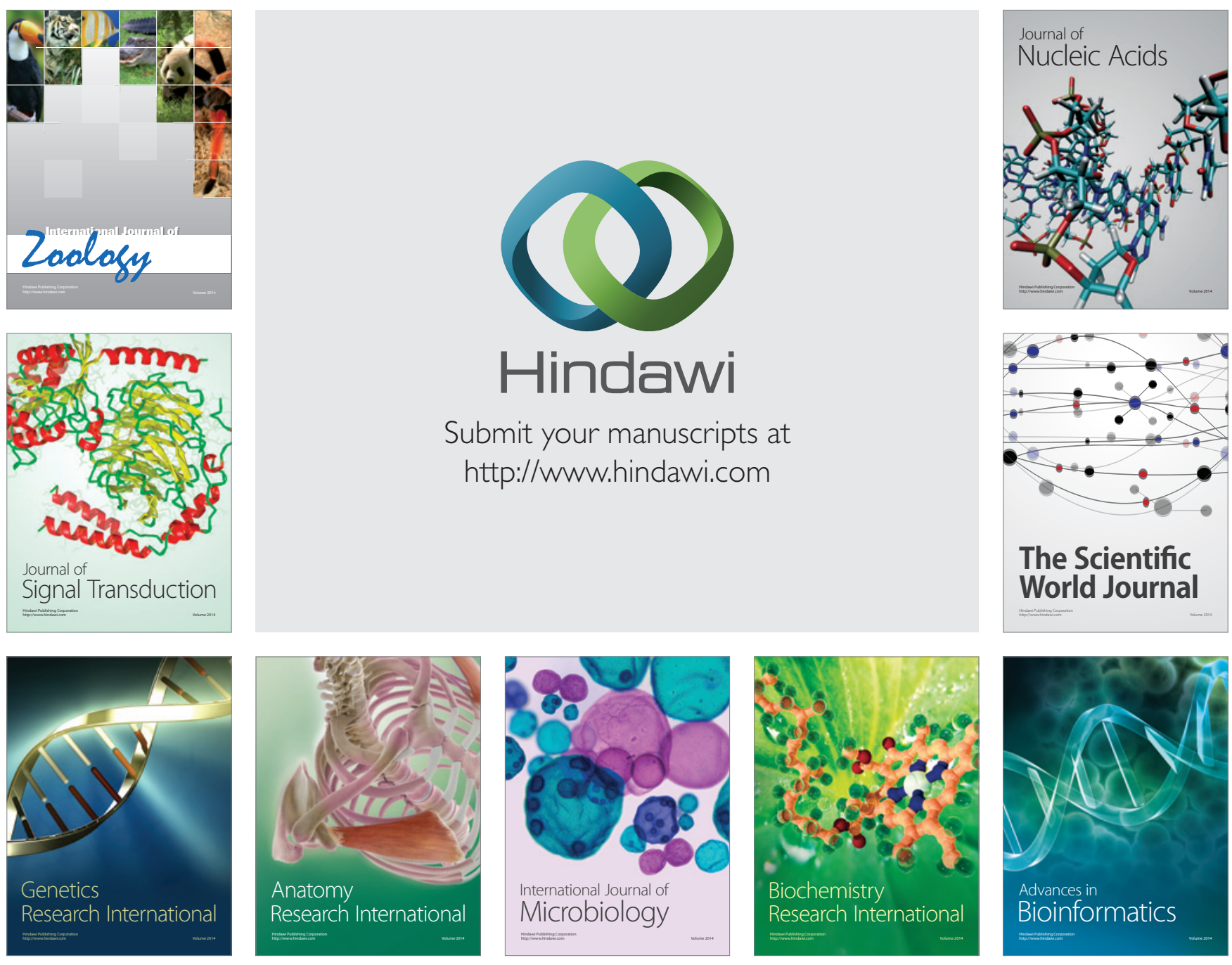

The Scientific World Journal
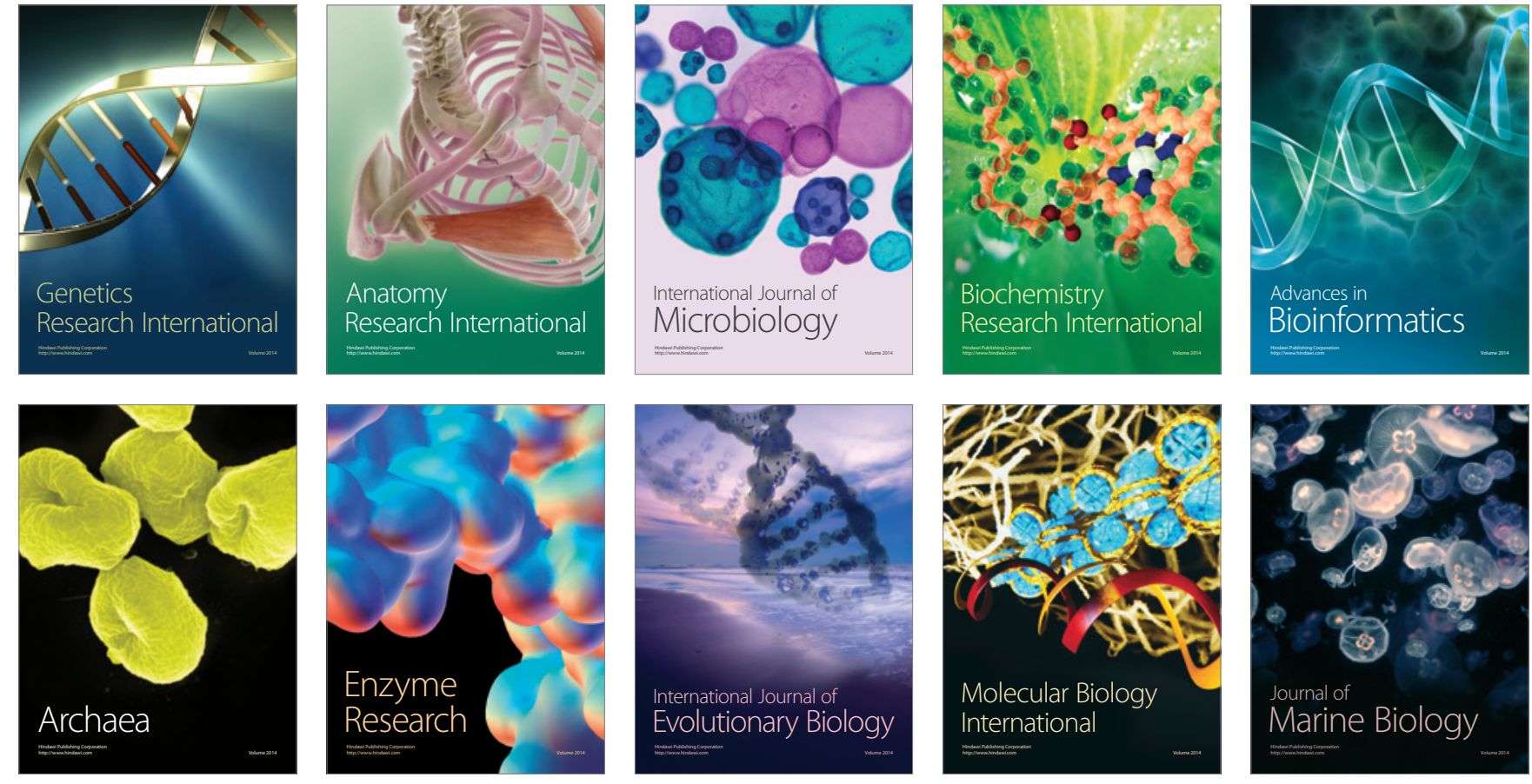